\section{La Révolution française}

Cahiers de l'Institut d'histoire de la Révolution française

9 | 2015

Citoyenneté, république, démocratie dans la France de la Révolution

\title{
Aux armes, citoyens! Questions autour du droit naturel et du monopole de la violence dans la période de transition 1770-1795
}

\section{Bernard Gainot}

\section{OpenEdition}

\section{Journals}

Édition électronique

URL : http://journals.openedition.org/lrf/1481

DOI : $10.4000 / / r f .1481$

ISSN : 2105-2557

\section{Éditeur}

IHMC - Institut d'histoire moderne et contemporaine (UMR 8066)

Référence électronique

Bernard Gainot, «Aux armes, citoyens! Questions autour du droit naturel et du monopole de la violence dans la période de transition 1770-1795», La Révolution française [En ligne], 9 | 2015, mis en ligne le 16 novembre 2015, consulté le 02 mai 2019. URL : http://journals.openedition.org/lrf/1481 ; DOI : $10.4000 /$ Irf. 1481

Ce document a été généré automatiquement le 2 mai 2019.

(c) La Révolution française 


\title{
Aux armes, citoyens! Questions autour du droit naturel et du monopole de la violence dans la période de transition 1770-1795
}

\author{
Bernard Gainot
}

Une milice bien organisée étant nécessaire à la sécurité d'un État libre, le droit qu'a le peuple de détenir et de porter des armes ne sera pas

transgressé.

1 Tel est le deuxième amendement de la Constitution des États-Unis d'Amérique, adopté en 1791 avec dix autres articles qui constituent une déclaration des droits, en préambule au texte constitutionnel. Il est considéré jusqu'à nos jours comme un des legs les plus précieux de la "Révolution américaine » et, pour une bonne partie de l'opinion outreatlantique, imprescriptible. On peut certes souligner les réserves et les limites posées à l'exercice de ce droit dès l'époque de sa formulation, liées pour la plus grande part aux contours précis de la notion de «peuple souverain». Tel n'est pas le propos de cette contribution qui voudrait partir de la rigoureuse application du jusnaturalisme moderne et du constitutionnalisme républicain, dont cet amendement est la synthèse, pour en souligner la portée symbolique implicite, la représentation de l'homme libre étant toujours liée à la détention d'une arme (généralement un fusil, ce qui déplace aussi, en la "modernisant», la signification réelle de cette symbolique du «citoyen armé » empruntée au républicanisme classique). L'invocation de la sécurité renvoie aux principes du droit naturel, le droit des colons de posséder des armes étant une manifestation du droit de résistance à l'oppression, davantage que le nécessaire recours à l'auto-défense dans un environnement hostile, mais les deux déclinaisons du principe étaient dès cette époque confondues sous l'invocation de la « loi naturelle» :

C'est un droit naturel que les gens se sont réservés, confirmé par la Déclaration des droits, de conserver une arme pour leur propre défense ; et, [...] cela est fait pour 
être utilisé lorsque les sanctions légales sont jugées insuffisantes pour restreindre

la violence de l'oppression ${ }^{1}$.

Quant à l'autre grande référence implicite du deuxième amendement, celle du constitutionnalisme républicain, il renvoie à la tradition classique, que Victor Davis Hanson avait transcrite comme « modèle occidental de la guerre », qui liait étroitement le « militarisme civique » et la conception juridique de la liberté. Depuis la projection sur les champs de bataille antiques de la Cité grecque avec les bataillons hoplitiques :

La guerre occidentale est souvent un prolongement de l'idée de la politique, plutôt qu'un simple effort pour obtenir un territoire, un statut personnel et des richesses, ou pour se venger. Les armées occidentales attachent un grand prix à l'individualisme et les critiques ou les plaintes des civils auxquelles elles sont souvent exposées sont de nature non pas à éroder, mais à améliorer leur capacité de faire la guerre ${ }^{2}$.

3 Certes, le champ de bataille n'est pas le forum, mais il en est à la fois la condition et la projection; et c'est dans cette indétermination même, entre le danger externe et la corruption interne, entre l'état civil et l'état militaire, comme disait Diderot $^{3}$, que le «militarisme civique » s'élève contre une des conséquences du processus de « révolution militaire » entamé dans les États occidentaux depuis la $\mathrm{XV}^{\mathrm{e}}$ siècle ${ }^{4}$; la concentration de la fabrication, de la circulation, et de la détention des armes, par les institutions spécialisées de l'État moderne, pour tendre au monopole de la violence publique. Je chercherai donc, dans un premier temps, à faire un bilan de cette quête du monopole par la monarchie administrative à la veille de la Révolution française. La transition révolutionnaire inaugure une nouvelle donne dans cette recomposition du monopole, avec le transfert de souveraineté de l'État monarchique au " peuple souverain ». Dès lors, on peut esquisser un parallèle entre les républiques américaine et française dans la diffusion large du principe de la citoyenneté armée. Ce sera le deuxième moment. L'issue est toutefois bien différente, et il n'existe aucune transcription du deuxième amendement dans les modalités d'application du droit primordial à la sûreté, qui est un des droits fondamentaux (article 2 de la Déclaration des droits de l'Homme, avec la liberté, la propriété, et la résistance à l'oppression) dans le droit positif français. À travers la requalification de la catégorie de "peuple ", c'est toute une mécanique du contrôle de la fabrication et de la circulation des armes héritée des instruments du pouvoir monarchique qui est ainsi redéfinie. Je montrerai dans un troisième temps comment cette redéfinition est parallèle à une requalification de la citoyenneté, essentiellement distincte du substrat communautaire sur laquelle se fonde l'auto-défense.

\section{Le bilan d'un siècle de quête du monopole sur la diffusion des armes par la monarchie administrative}

4 Si la définition générale de l'objet («Armes: instruments servant à attaquer et à se défendre $\left.{ }^{5} »\right)$ est suffisamment vague pour laisser une grande latitude d'interprétation de son usage, la distinction armes blanches/armes à feu est toutefois devenue cruciale pour toute la législation sur les armes à feu. La législation pour le contrôle des armes se durcit à la fin du XVII ${ }^{e}$ siècle. L'Édit de 1666 devient la référence absolue pour tous les textes ultérieurs ${ }^{6}$. Il donne la liste des armes prohibées, des peines encourues pour tout manquement à la règle, des conditions grâce auxquelles les citadins peuvent continuer à utiliser les armes licites. Ces dispositions inaugurent de fait une vaste entreprise de 
désarmement. Pour identifier clairement les moyens de cette entreprise, il faut distinguer la législation sur la vente d'armes, et la législation sur le port d'armes. Le commerce des armes relève de la juridiction réglementaire des métiers jurés. Les armuriers sont spécialisés dans les armes défensives ; assimilés aux heaumiers, on trouve principalement dans leurs boutiques des cuirasses, et toutes sortes d'armes d'hast, hallebardes, pertuisanes, guisarmes... Ils font progressivement figure d'antiquaires, par rapport aux arquebusiers, chez lesquels on trouve essentiellement, comme leur nom l'indique, des armes à feu, et des "bâtons", ce terme désignant toute arme offensive. C'est dans les boutiques d'arquebusiers que l'on trouve les fusils simples, communément appelés " fusils de chasse », des fusils à deux coups que les arquebusiers fabriquent souvent euxmêmes? .

5 Les armes blanches, qui ne sont plus que des armes d'appoint des armes à feu (ce qui ne préjuge en rien de leur létalité), se rencontrent de plus en plus rarement chez les couteliers. Dès lors, le commerce de ceux-ci va se tourner vers les instruments de chirurgie et les couteaux à usage domestique, alors que l'arme blanche va devenir l'article principal des fourbisseurs. Le métier principal de ces derniers est de fourbir et de garnir la lame, de dorer la garde, la hampe et les poignées des épées, des dagues, des sabres, des piques, des haches, et des couteaux de chasse ${ }^{8}$. Ces derniers instruments peuvent devenir des armes meurtrières, à tel point que le maréchal de Puységur, secrétaire d'État à la guerre en juillet 1789, estimait que ces « couteaux de chasse devraient être substitués aux épées, et seraient beaucoup plus utiles dans les combats. »

$6 \mathrm{Au}$ début du règne de Louis XVI, il y a environ 200 maîtres fourbisseurs à Paris, 120 couteliers, 70 arquebusiers, et une quarantaine d'armuriers9. Le marché des particuliers est donc beaucoup plus tourné vers les armes blanches que vers les armes à feu. Mais c'est parce que l'État va étendre son contrôle sur ces dernières par la multiplication des manufactures d'armes dans le Royaume. L'Édit de 1666 opérait déjà une distinction soigneuse entre les armes destinées aux militaires, et les armes destinées aux civils. La vente des baïonnettes, par exemple, est interdite à tous les sujets du Royaume; il y a un statut particulier pour les «baïonnettes à ressort, qui se mettent au bout des armes à feu pour l'usage de la guerre.» On définit les artisans et les clients qui peuvent manipuler ce type de baïonnette : ce sont les ouvriers spécialisés, dont le métier va prendre par la suite toute son ampleur dans les manufactures d'armes. Ils ne peuvent vendre de baïonnettes qu'aux officiers. Au XVIIIe siècle, les maîtrises n'approvisionnent plus les troupes que de manière conjoncturelle, en temps de guerre, alors que se créent des pénuries dans les manufactures ${ }^{10}$. Le terme de "manufacture d'armes" va se confondre de plus en plus avec celui d' " arsenal ", qui désignait au XVII ${ }^{e}$ siècle un espace fermé, dans les grands ports militaires (Brest, Rochefort, Toulon, Marseille pour les galères, puis Lorient et Cherbourg), pour, entre autres, la préparation de l'armement des vaisseaux de guerre. Tandis que les fonderies de canons de marine se détachaient des arsenaux portuaires, à Indret ${ }^{11}$ sur la Loire, Ruelle sur la Charente, ou Rennes-Redon sur la Vilaine, les ateliers de la petite métallurgie se transforment en industries de guerre, et les manufactures de Charleville, Tulle, Saint-Étienne travaillent à l'entreprise pour l'État sous le contrôle des inspecteurs d'artillerie. La production est progressivement normalisée jusqu'aux fusils réglementaires, dont la norme de fabrication et la qualité sont garanties par un poinçon. Pour contrôler la qualité, il faut faire " éprouver » les canons des armes à feu. C'est le «test de qualité » obligatoire pour les armes militaires. À la fin du XVIIIe siècle, ce fusil réglementaire est le fusil d'infanterie modèle 1777, mis au point 
par l'Inspecteur Gribeauval. Toutefois, d'autres types de fusils réglementaires, plus anciens, pouvaient circuler, mais leur usage était périodiquement contrôlé par les inspecteurs et les commissaires, rouages principaux du monopole d'État sur la circulation des armes de guerre ${ }^{12}$.

Une autre forme de contrôle était le stockage d'armes de guerre dans des bâtiments fortifiés à proximité des enceintes urbaines (le « magasin de la Bastille » qui est l'Arsenal de Paris, l'arsenal à la confluence de la Saône et du Rhône à Lyon) ou dans les placesfortes à proximité des frontières (Strasbourg, Metz, Douai, Grenoble...). C'est à ces bâtiments enclos que l'on donne le nom d' " arsenaux de terre "; ils seront naturellement au centre des mouvements révolutionnaires. L'Édit de 1666 avait déjà cherché à définir les critères qui permettaient l'autorisation de vente et de circulation de certaines armes. Les critères objectifs sont la longueur de l'arme et du canon; la dague, épée courte à lame large, le poignard, couteau dont la lame ne dépasse pas $25 \mathrm{~cm}$, le pistolet de poche, sont des armes qui peuvent être facilement dissimulées. À ce titre, elles présentent une menace grave. Les textes réglementaires sont convergents ; il faut proportionner l'usage privé à la taille. L'arme doit être suffisamment longue, ou volumineuse, pour ne pas être dissimulée. L'objectif de l'État est l'exposition publique des armes portatives, ce qui rend plus facile le contrôle de leur circulation. Le monarque tend par ailleurs à réserver l'usage et la qualité des armes à ses soldats, par la multiplication des manufactures et des arsenaux, bien visibles dans l'espace urbain, mais bien vulnérables en cas de défaillance de l'appareil administratif de contrôle. Dans les villes, outre les militaires, l'usage se restreint aux officiers de police et de justice. Les fourbisseurs qui souhaitent vendre des armes aux officiers, ou aux représentants des régiments, de passage ou en garnison, doivent se soumettre à des critères qui vont tendre de plus en plus vers la production de masse, comme la standardisation réglementée en usage pour les manufactures. Ils peuvent continuer à satisfaire une commande spéciale individualisée, mais celle-ci demande un travail long et minutieux, qui n'est pas répété pour chaque arme. Se crée ainsi un marché pour les armes de très grande valeur, mais qui est de plus en plus dissocié de la production courante.

L'Édit de Turgot de 1776 va réunir arquebusiers, couteliers et fourbisseurs en une seule communauté. C'est une tentative de contrôler étroitement la diffusion des armes. L'ordonnance de police du 21 mai 1784 durcit la réglementation, en interdisant les épées, à une période où le port de l'épée se généralise au sein d'une population qui conteste le monopole du port de cette arme par la noblesse ; jusque-là, c'étaient les cannes-épées ou «cannes à dard» qui contournaient le privilège social. Ces cannes étaient d'ailleurs strictement prohibées, à la fois pour cette infraction au privilège, mais également parce qu'elles sont considérées comme l'arme du crime par excellence. Il y a donc tout un jeu de la représentation de l'homme armé dans les textes réglementaires, la considération allant de pair avec la professionnalisation. Le désarmement de la population civile, sous la monarchie administrative, est rigoureusement parallèle à l'armement des soldats et à la professionnalisation du métier militaire.

9 Toutefois, cette séparation ne signifie nullement un libre usage des armes par les militaires ; bien au contraire, la quête du monopole de la violence concerne également ces derniers, au premier chef, pourrait-on dire. Les soldats sont souvent impliqués dans des rixes, dans les grandes métropoles, ou dans les villes de garnison; ils participent parfois à des activités illicites (contrebande, maisons de jeu, prostitution). Le pouvoir monarchique a cherché à surveiller et à contrôler les mouvements et les activités de ses militaires en 
les concentrant dans des casernes, autre bâtiment sensible du décor urbain. Le résultat n'est pas toujours probant, ainsi qu'en témoigne l'exemple du régiment des Gardes françaises qui, bien que logés dans vingt-et-une casernes dispersées dans la capitale, se dissout largement dans la population civile ${ }^{13}$. Cette «communautarisation» des régiments n'est d'ailleurs pas propre aux Gardes-françaises, aussi marquant que soit le rôle qu'ils vont tenir dans les premières journées révolutionnaires. Bien des villes de garnison (Rennes, Nancy, Strasbourg, Brest, Toulon) qui vont connaître des troubles sociaux et des mutineries au cours des premiers mois de la Révolution, connaissent ce phénomène.

10 À Paris, les Gardes-françaises ne doivent pas « vaguer la nuit hors de leur quartier » après 6 heures du soir en été, et 9 heures du soir en hiver, « avec épées et autres armes, s'ils n'ont l'ordre par écrit de leur capitaine ». Durant la journée, ces soldats ne peuvent se déplacer armés hors de leurs quartiers (le quartier de la caserne) s'ils sont plus de quatre. La réglementation s'étend progressivement à tous les soldats en permission dans la capitale. Les soldats tendent à se confondre avec la population, tout en continuant à porter l'épée au côté. Le pouvoir royal leur interdit également de se faire employer comme domestiques dans des maisons particulières. Ils portent l'épée en même temps qu'ils portent la livrée, ce qui est interdit.

11 Une tension très marquée existe donc à la fin de l'Ancien Régime, entre la tendance de plus en plus marquée du pouvoir royal vers le renforcement du contrôle de la fabrication et du port d'armes, vers la quête du monopole de leur usage, et les aspirations de la population française, qui a de plus en plus le goût des armes ${ }^{14}$. Le bourgeois (au sens de celui qui a une situation établie et une résidence fixe) veut posséder une arme, même au mépris des ordonnances, pour pouvoir l'exhiber en public de façon ostentatoire, et en faire des usages multiples. Il accepte mal l'autorisation pour port d'armes. Il tend à reproduire des attitudes qui étaient auparavant l'apanage exclusif de la noblesse, comme le port de l'épée, qui n'est plus la marque exclusive d'une certaine classe. Cette démocratisation de l'usage se double d'une revendication du droit naturel ; la possession particulière d'une arme est une prérogative du citoyen.

\section{Dilution du monopole et de la professionnalisation, prolifération des armes}

12 En juillet 1789, se produit le basculement décisif. Mais la secousse, dont l'épicentre se trouve dans la capitale, a touché aussi la province. 20000 soldats, dont 3500 cavaliers (Royal-Dragons, Royal-Cravates, Royal-Allemand, Hussards de Bercheny et d'Esterhazy), s'installent dans les bourgs voisins de la capitale. Parmi les régiments d'infanterie, on compte plusieurs régiments étrangers, dont les régiments suisses de Salis-Samade, Reinach, Diesbach et Chateauvieux. Outre les troupes appelées en renfort, le nouveau secrétaire d'État à la guerre, le maréchal De Broglie, peut compter sur les troupes permanentes faisant partie de la maison du Roi, les 3200 Gardes-suisses qu'il avait commandés, et les 3600 Gardes françaises. Le 12 juillet est la journée décisive ; les heurts au jardin des Tuileries entre le Royal-Allemand et les manifestants qui protestent contre le renvoi de Necker amènent un redéploiement du dispositif d'intervention. Au cours de celui-ci, sur les boulevards, un affrontement oppose les Gardes-françaises et les cavaliers du Royal-Allemand. Tandis que les Gardes-françaises passent du côté des manifestants, la démoralisation gagne l'ensemble des troupes. 
Les patrouilles du guet et de la Garde de Paris sont désarmées. Plusieurs boutiques de vente d'armes sont dévalisées. Dans la nuit du 12 au 13 juillet, apparait une milice bourgeoise, dont la levée se fait dans la plus totale confusion; seule la cocarde bleue et rouge, aux couleurs de la ville de Paris, permet de distinguer ces « citoyens armés », des bandes de pillards qui parcourent les rues. Pour les encadrer, le Comité des Électeurs parisiens fait appel aux Gardes-françaises. Les effectifs explosent, et le chiffre de 48000 citoyens est bien vite atteint, mais il faut leur fournir des armes. Le bâtiment du Garde-Meuble, sur la place Louis XV, a d'abord été dévalisé dans la matinée du 13 juillet. Mais on trouve surtout des pièces de collection, tout comme dans les nombreuses boutiques d'armuriers pillées, si on en juge par l'allure étrange que présentent les premiers défilés de la garde citoyenne, avec un armement hétéroclite, les pertuisanes, les hallebardes, et autres espontons, brandis par des citadins en civil, où les bonnets et chapeaux se mêlent aux heaumes et aux cuirasses ${ }^{15}$. La foule parisienne va ensuite se tourner vers les Invalides, où sont stockés 10000 fusils. Le bâtiment est investi dans la matinée du 14 juillet, les fusils sont répartis entre les assaillants, et tous ne furent pas récupérés par les gardes nationaux. Douze pièces de canons sont saisies, ce qui constitue la prise d'armes la plus précieuse, et la plus symbolique du transfert de souveraineté. D'ailleurs, dans les jours qui suivent, ces pièces sont transportées à Montmartre et mises à la disposition de la nouvelle Commune de Paris, geste et dépôt qui resteront emblématiques du transfert révolutionnaire du pouvoir pendant la plus grande partie du $\mathrm{XIX}^{\mathrm{e}}$ siècle, jusqu'en mars $1871^{16}$. On restait toutefois dans le registre symbolique si on ne dispose pas de la poudre pour actionner fusils et canons. Or, la poudre est entreposée normalement à l'Arsenal ; le gouverneur de la Bastille, le marquis De Launay, vient de la faire préventivement transporter dans les souterrains de la forteresse.

L'investissement de cette dernière, dans l'après-midi du 14 juillet, n'est que la conclusion d'une suite d'événements qui ponctuent la perte, par la monarchie, du monopole de la violence légitime. C'est, en soi, le fait révolutionnaire capital, relié à plusieurs situations de rupture pour la force armée ; la mutinerie des Gardes-françaises, noyau d'une milice citoyenne soustraite au contrôle du monarque pour être placée sous celui d'une autorité collective élue, la dissémination désordonnée des armes offensives, dont une grande partie échappe à la nouvelle Garde nationale pour se retrouver dans les mains d'individus ou de groupes qui considèrent que leur possession est une dimension constitutive du nouvel ordre civique.

Dans les semaines qui suivent, tandis que les troupes réglées cantonnées par le gouvernement autour de Paris retournent dans leurs garnisons, la réplique de la rupture révolutionnaire s'opère un peu partout en province. Le 16 juillet à Rennes, les fantassins du régiment d'Artois et les dragons du régiment d'Orléans expriment leur malaise. Le commandant local, le marquis de Langeron, doit s'enfuir. Les régiments se réunissent aux jeunes gens de la milice citoyenne pour former ultérieurement une " Armée nationale ${ }^{17}$. » Le pouvoir monarchique perd le contrôle de la force armée. La nouvelle de la prise de la Bastille parvient le dimanche 19 juillet à Strasbourg. Une troupe de 500 ou 600 émeutiers armés de haches, parmi lesquels un grand nombre de gens de tous corps de métiers, prend d'assaut l'Hôtel de Ville.

La confusion règne; les soldats montrent peu d'ardeur à réprimer les émeutiers qu'ils connaissent bien, qui appartiennent aux mêmes milieux sociaux qu'eux ${ }^{18}$. Le gouverneur de la province d'Alsace, Rochambeau, craignant cette conjonction du malaise militaire et du soulèvement populaire, fait distribuer aux bourgeois 500 hallebardes et 12000 sabres, 
mais se garde bien de donner les clefs de l'Arsenal aux membres du comité provisoire qui fait office de municipalité. Une Garde nationale bourgeoise se constitue sur le modèle parisien. Face à celle-ci, le commandant adopte une attitude prudente, cherchant au moins à conserver le monopole des armes de guerre, ne lâchant que les armes blanches symboliques :

Les nouvelles de la capitale avaient une réaction très prompte dans la bourgeoisie. Cette dernière, qui s'était contentée des armes blanches que je leur avais fait délivrer des arsenaux, voulut être équipée de fusils. Je portai la demande au gouvernement qui m'autorisa de leur en donner mais le moins qu'il serait possible, pour l'usage des patrouilles particulières. Ils se contentèrent de 600 fusils qui étaient plus que suffisants pour armer leurs gardes ${ }^{19}$.

Le contrôle de la situation, et la transition dans l'ordre, ne sont pas toujours possibles, bien loin de là. À Lyon, le premier échevin Imbert-Colomès, émanation du Consulat, institution urbaine de l'Ancien Régime, a fait lever des compagnies de Volontaires, recrutés parmi les "bons citoyens », et vite qualifiés de « muscadins ». Ils sont envoyés au secours des seigneurs du Dauphiné lors de l'épisode de la Grande Peur. Fin juillet, à l'occasion des émeutes contre les octrois, un semblant de force patriote rivale des Volontaires, a tenté de s'organiser. Un premier assaut est lancé contre l'Arsenal, situé rive de Saône sur la presqu'île, mais il est repoussé. Le Consulat ordonne le désarmement de la population ${ }^{20}$.

En janvier 1790, une assemblée de citoyens se réunit pour élire de nouvelles autorités municipales, et pour organiser une Garde nationale. Imbert-Colomès doit s'incliner et convoquer les assemblées de sections pour élire les officiers de la nouvelle force patriote. Mais il conserve les compagnies de volontaires, leur confiant le soin de garder l'Arsenal de Lyon, poste hautement stratégique. Le 7 février 1790, un rassemblement parvient à déborder les Volontaires, et à investir le bâtiment ${ }^{21}$. Les dépôts d'armes sont pillés. Le soir, Imbert-Colomès, le pivot de la résistance d'Ancien Régime s'enfuit à Bourg-enBresse. Les compagnies de Volontaires sont dissoutes. Cette prise de l'Arsenal de Lyon est aussi décisive pour la poursuite de la dynamique révolutionnaire que l'avait été la prise de la Bastille (nullement symbolique, puisque s'emparer des magasins à poudre était autrement plus efficient qu'ouvrir quelques cachots, mais qui s'est penché sur cette question ?). Dès lors, c'est l'extension du processus révolutionnaire à tout le Sud-Est qui est relancé.

19 La question de la prolifération des armes a été au cœur des débats de l'Assemblée nationale, au sujet de la suppression du droit exclusif de chasse réservé à la noblesse, une des décisions importantes prises lors de la nuit du 4 août 1789. Immédiatement, la question du port d'armes est posée, et on s'alarme des dangers que ferait courir à l'ordre public la liberté illimitée de posséder un fusil. Au cours de la séance du 7 août, le précédent anglais est rappelé pour déterminer le cadre réglementaire : « fixer la quotité de terre que devra posséder celui qui voudra avoir le port d'armes ${ }^{22}$.» Ainsi le port d'armes est-il directement référé à la propriété, ce que ne contestent nullement les adversaires de toute limitation du port d'armes: «l'Assemblée nationale n'a pas le droit d'ordonner à un citoyen de ne pas défendre sa propriété ", avertit Buzot en dénonçant toutefois toute réglementation comme une fabrique de privilèges. L'universalisation du droit dépasse nettement le domaine de la défense des biens pour être généralisé à la défense des personnes : « quel sera celui à qui vous la refuserez ? Ce privilège ne sera-t-il pas humiliant, et ne sera-t-il pas aussi injuste que l'injustice à laquelle vous voulez 
remédier ? ", poursuit Buzot. Terrain miné, estime la majorité de l'Assemblée, derrière Target :

Dans la nuit du 4, l'Assemblée a supprimé le droit exclusif de la chasse; son invention n'a pas été de rien déterminer sur l'espèce des armes dont on pourrait se servir pour chasser. Le port d'armes doit être l'objet d'une délibération séparée ${ }^{23}$.

Pourtant, ce débat, fort instructif pour notre propos, et de grandes conséquences pour l'avenir, n'eut jamais lieu, comme si la tension inhérente à la transcription du droit naturel en énoncés de règles de droit positif s'était avérée trop forte. Ce qui engendre la paralysie née du face-à-face entre ceux qui, tel le tout nouveau garde des Sceaux, Champion de Cicé, viennent réclamer des mesures d'urgence contre le "désordre armé » qui menace les propriétés dans les provinces (c'est naturellement le spectacle de la Grande Peur qui est scénarisé pour appuyer cette demande d'ordre et de tranquillité publics) et ceux qui, tel Mirabeau, s'insurgent préventivement contre toute «loi de police » qui irait à l'encontre d'une prérogative de l'individu pour défendre bien plus qu'un loisir, bien plus qu'un bien, un droit à l'existence, à travers la préservation des récoltes ${ }^{24}$. C'est Clermont-Tonnerre qui esquisse la position destinée à préserver la majorité essentielle à l'adoption du compromis du 11 août sur les droits féodaux :

Vous n'avez rien décidé relativement aux armes. Cette question vous sera bientôt soumise. Empêchons que les moyens employés pour défendre les propriétés nuisent à la chose publique [...]. Ne nous effrayons pas sur les suites qu'on croit devoir craindre de la liberté des armes. Il ne faut pas s'étonner que le ressort de la liberté, comprimé depuis plusieurs siècles par le pouvoir arbitraire, se détende aujourd'hui avec impétuosité. Mais tout va rentrer dans l'ordre ${ }^{25}$.

Or, contrairement à cette prédiction optimiste et rassurante, c'est le trouble, et par conséquent, l'insécurité, qui vont se généraliser.

\section{Elargissement de la citoyenneté, multiplication des prises d'armes}

21 La dynamique du processus révolutionnaire et de la prolifération des armes ne se limitaient, $\mathrm{ni}$ au territoire métropolitain, ni aux catégories juridiques constitutionnellement définies comme aptes à en détenir et à en user. La France, se représentant de plus en plus comme un Empire, les grandes métropoles coloniales inscrivaient dans leurs projets d'urbanisme les bâtiments publics qui reproduisaient le nouvel espace urbain de l'Europe occidentale. Les ouvrages de défense comme la fortification des rades se modernisaient, les casernes construites en dur illustraient un nouveau système défensif fondé sur les troupes professionnelles davantage que sur les milices, tandis que l'Arsenal, également construit en dur, traduit le monopole royal dans l'espace urbain. Ainsi, Moreau de Saint-Méry décrit-t-il à la veille de la Révolution l'Arsenal dans la ville du Cap Français, la grande ville du Nord de la colonie de SaintDomingue :

Dans l'Ouest de la batterie circulaire, est le parc d'artillerie, qui s'étend jusqu'à la rue Picolet, et qui la borde, allant du Sud au Nord, jusqu'à la petite rue de l'Arsenal [...] le parc d'artillerie a 90 toises du Nord au Sud, sur environ 50, de l'Est à l'Ouest. C'est durant la guerre de 1778 qu'on l'a formé et qu'on l'a clos d'un mur à hauteur d'appui, avec des pilastres de distance en distance, qui porte une clairevoye en fer ${ }^{26}$.

La façon dont le monopole va échapper au pouvoir, représenté (au sens fort de « rendre présent une absence») en l'espèce, comme dans les autres provinces françaises 
périphériques du domaine royal, par un gouverneur, se confond avec la révolution coloniale, et il serait bien trop long de reproduire ici ce processus. Contentons-nous de rappeler les étapes marquantes de la perte du monopole, et les sources de la prolifération des armes. C'est la révolte coloniale blanche, et non la révolte des esclaves d'août 1791, comme le répètent en boucle des polygraphes dédaigneux de la logique chronologique, qui met à mal les pouvoirs du gouverneur et inaugure les prises d'armes en juillet 1790 . L'un des premiers historiens de la Révolution de Saint-Domingue, le général Pamphile de Lacroix, rend compte de la subversion des pouvoirs, et du transfert subséquent du commandement de l'arsenal et de l'artillerie de Port-au-Prince, après l'assassinat du colonel De Mauduit, le représentant légal du gouverneur De Blanchelande à la tête de la force armée, par la foule révolutionnaire le 30 juillet 1791 :

Au milieu des accents bruyants d'une joie féroce, un second Te Deum fut chanté pour remercier l'Être Suprême de l'heureuse révolution qui venait de s'opérer; elle était complète. Les attributions de $\mathrm{M}$. De Blanchelande furent usurpées par M. De Caradeux, habitant du Port-au-Prince, sous le titre de capitaine-général de la Garde nationale. Les fonctions de lieutenant de roi furent envahies par la municipalité. Un matelot déserteur, nommé Praloto, maltais d'origine, se substitua à M. de la Merveillière, chevalier de saint-Louis, inspecteur des fortifications; il ajouta aux canonniers de la troupe de ligne un corps nombreux d'artillerie bourgeoise ${ }^{27}$.

Nombreux étaient par ailleurs les hommes de couleur libres qui servaient dans les milices coloniales; nombre de ceux-ci, qui avaient acquis une expérience militaire, soit comme réserve territoriale de défense des côtes, soit dans l'expédition de Savannah lors de la guerre d'Amérique, devinrent officiers dans la Garde nationale ${ }^{28}$. Le pouvoir colonial avait cherché à préserver son monopole sur les armes de guerre, en réservant aux régiments réglés l'usage des fusils réglementaires et des canons. Les miliciens, comme ce fut le cas en Nouvelle-France à l'époque des guerres contre les Anglais et les amérindiens, étaient généralement équipés de fusils dits " de traite ", autrement appelés " fusils boucaniers » dans les Antilles, qui ont un canon très long, et une platine ronde. Ils étaient également fabriqués dans les manufactures métropolitaines, principalement à Saint-Etienne, et secondairement à Tulle, puis expédiés à Rochefort, où transitent la plupart des armes à feu destinées aux colonies; la grande différence avec les fusils réglementaires est que les contrôleurs n'éprouvent pas les fusils de traite, d'où leur moindre qualité, et les nombreuses fraudes ${ }^{29}$.

Enfin, une troisième source d'approvisionnement, et non la moindre, tout particulièrement lorsque les insurgés noirs établirent leurs camps sur les mornes boisés qui jouxtent la frontière avec la colonie espagnole, fut la contrebande. En provenance essentiellement des États-Unis - mais aussi des Antilles espagnoles et hollandaises, cette contrebande s'inscrit dans l'économie politique de la zone caribéenne, et singulièrement dans les brèches de plus en plus béantes de l'Exclusif colonial à la fin de l'Ancien Régime ${ }^{30}$. Le produit le plus sensible, et le plus recherché au cours de ce trafic, c'est la poudre, dont l'autorité coloniale avait toujours surveillé étroitement les dépôts secrets. Sans surprise, le monopole sur les armes connaît un destin parallèle à celui du monopole commercial, et du gouvernement colonial. Le transfert du contrôle de l'armement, de l'autorité monarchique et de ses représentants institutionnels, vers les instances décentralisées émanant des troubles révolutionnaires, municipalités, gardes nationales, chefs de bandes insurgées, s'accompagne toutefois aux Antilles d'une transgression symbolique particulièrement significative; la figure de l'homme armé se confond avec celle de 
l'esclave noir insurgé. La révolution des couleurs double la révolution des pouvoirs, comme le manifeste la gravure emblématique de "la citoyenne Rollet ", d'après Fougéa, qui date de la reconquête républicaine de la Guadeloupe en 1794, et de l'abolition de l'esclavage dans son sillage.

Le Nègre armé est destiné à exalter les vertus guerrières de ces nouveaux Combattants de la Liberté [...]. Ce sont les adieux d'un Noir armé d'un fusil et tenant son fils dans ses bras, tandis que sa femme ne peut retenir ses larmes. Cette œuvre, dans un goût néo-classique, est très proche d'un dessin de Fabre de la même époque représentant les adieux d'Hector et d'Andromaque. Nul doute que pour le spectateur cultivé de l'époque ne se fit le rapprochement. On a donc ici des Troyens en habits d'esclaves nègres, tandis que d'habitude, on représentait plutôt les Républicains en habits de Romains ${ }^{31}$.

La figure du commissaire Léger-Félicité Sonthonax, qui proclame l'abolition de l'esclavage dans le nord de Saint-Domingue le 29 août 1793, est également attachée à une prise d'armes symbolique. Mais les images se télescopent; alors que le récit national haïtien retiendra le geste du d'armes se revendiquant du droit naturel, que la possession d'un arme est la garantie de la conservation de la liberté, il semble que la scène se soit déroulée en un autre temps, avec des visées et une gestuelle différentes. C'est lorsque Sonthonax est envoyé pour une seconde mission par le Directoire, et qu'il arrive au Cap le 11 mai 1796, qu'il distribue 20000 fusils de munition neufs aux « nouveaux libres », nous dit Madiou, mais pas de façon indiscriminée ${ }^{32}$. Les destinataires, ce sont les soldats de Toussaint-Louverture, amalgamés avec les troupes européennes du gouverneur Laveaux qui ont survécu aux aléas des conflagrations civiles et des combats, tant contre les Anglais que contre les Espagnols, et organisés en demi-brigades, sur le modèle des armées métropolitaines. En remettant chaque fusil à chaque combattant, le commissaire dit: "Voici la liberté que te donne Sonthonax; celui qui t'enlèvera ce fusil voudra te rendre esclave.» Mais le discours est tout autre lorsque le commissaire s'adresse aux cultivateurs, les incitants au travail et à la responsabilité. D'ailleurs, Madiou n'hésite pas à taxer de « faute » la distribution d'armes aux cultivateurs de la vallée de l'Artibonite pour organiser leur auto-défense contre les Anglais ${ }^{33}$. La dissémination des armes de munition est dangereuse, la coïncidence de l'armement et de la liberté est effective, mais elle est limitée au cercle étroit des soldats, seuls véritables nouveaux citoyens. Ultérieurement, Toussaint va considérer la poudre de munition, tout à fait dans l'héritage des gouverneurs des provinces de l'Empire, comme le trésor véritable, la clef de la conservation du pouvoir, et va multiplier les dépôts secrets. Le naturaliste Descourtilz mentionne les grandes réceptions données en 1799 par le gouverneur aux capitaines « de bâtiments en relation de commerce avec la colonie, visant à en soutirer secrètement des poudres dont il sut toujours approvisionner, jusqu'à encombrement, ses magasins de réserve placés dans des endroits escarpés, quelquefois construits dans les creux de rochers inabordables ${ }^{34}$.»

La transgression par la prise d'armes est tout aussi manifeste dans le cas des femmes. Dès les journées d'octobre, la présence ostentatoire d'un armement, très hétéroclite à vrai dire, haches, piques et massues l'emportant nettement sur les rares fusils, dans les cortèges de femmes parisiennes, ponctue la symbolique ${ }^{35}$. Au milieu de la foule, un canon de campagne, fièrement escorté, est le signe tangible de la souveraineté populaire en actes $^{36}$. L'aspiration à un héroïsme de résistance populaire, qui ignore délibérément les déterminations sexuelles, fait partie de l'imaginaire collectif national, bien en place dans le contexte de la guerre d'Amérique. Comme témoignage particulièrement marquant, 
prenons cette tragédie en cinq actes et en vers composée par Sade en $1783^{37}$, qu'il chercha vainement à faire représenter en 1790 et en 1791 : Jeanne Laisné ou le siège de Beauvais. La véritable héroïne est Jeanne Hachette, une figure qui sera reprise et sublimée dans les manuels d'histoire de la Troisième République, inspirée des Chroniques de Froissart, dont Sade donne de larges extraits. L'épisode est celui de la résistance des habitants de Beauvais aux troupes bourguignonnes de Charles le Téméraire, alors que leur maire est tenté par la reddition. La fille du maire, Jeanne Laisné, anime cette résistance, prend les armes, encourage les femmes à faire de même, combat l'ennemi sur les murailles avec une hache, et succombe au cours de cet affrontement héroïque. L'auteur salue ce courage guerrier avec une exaltation patriotique qui rejoint bien le fond de l'opinion publique de cette époque, autant avide de réformes que de récits héroïques.

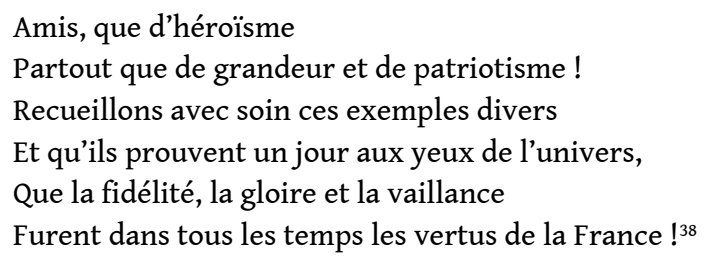

La pièce est accompagnée de notes très techniques sur l'art militaire, notamment sur l'artillerie, sur les fortifications. Manifestement, Sade veut montrer au public qu'il n'est pas un militaire d'opérette. Des simulations de bombardements ponctuent l'action. Les femmes sont armées de piques, elles se déplacent au son d'une musique guerrière ; un tel cortège semble préfigurer les foules féminines d'octobre 1789. Les bourguignons que combat Jeanne Laisné sont les alliés des anglais ; comment ne pas penser à Jeanne la Pucelle, dont elle serait la réplique, autre figure éminemment transgressive de vierge guerrière brandissant les attributs de la virilité ${ }^{39}$ ? À la fin, le corps transfiguré de Jeanne Laisné rejoint le Panthéon des héros morts pour la patrie, que les guerres de la Révolution vont bientôt placer au centre d'une nouvelle religion civique.

Le laurier, dites-vous, ne naît point sous nos doigts?

Ce n'est pas dans un siècle où les plus grands exploits,

Où les faits les plus beaux que l'histoire réclame

Viennent d'appartenir au seul bras d'une femme

Qu'il faudrait, ce me semble, accueillir ces discours :

Une femme fut donc utile à sa patrie ;

Laissez-moi l'imiter ; ah ! mon unique envie

Est d'obtenir comme elle une palme à ce prix, Et comme elle, en un mot, d'illustrer mon pays.

Sade anticipe les temps forts de l'élargissement de la citoyenneté; la pointe la plus avancée du mouvement fut la pétition des 304 citoyennes révolutionnaires adressée à l'Assemblée Législative le 6 mars 1792, pour solliciter l'autorisation de porter des armes :

1. La permission de nous procurer des piques, des pistolets et des sabres, même des fusils pour celles qui auraient la force de s'en servir, en nous soumettant au règlement de police,

2. De nous assembler les fêtes et les dimanches au Champ de la Fédération ou autres lieux convenables pour nous exercer à la manœuvre desdites armes[... ${ }^{40}$.

Toutefois, si on rencontre des clubs de femmes dans la plupart des grandes villes en 1791-1792, tous n'étaient pas sur des positions aussi radicales, à l'instar des Amies de la Vérité et de l'Egalité de Besançon, créé le 26 octobre 1792. Ces femmes qui avaient pourtant revendiqué explicitement le droit de vote dans les assemblées primaires, allaient se définir, en matière de défense nationale, comme pourvoyeuses d'uniformes et de bas pour les volontaires nationaux. C'est le vote ou le fusil, il ne paraît pas opportun de 
revendiquer de front les deux droits; ce faisant, le club de femmes de Besançon put continuer à exercer une certaine influence jusqu'en l'an II $^{41}$.

Une poignée de femmes patriotes va pourtant transgresser ces normes implicites de répartition des rôles sociaux pour endosser l'uniforme, et l'armement qui l'accompagne. La levée des bataillons de volontaires de l'an II, faite à la hâte, et qui vit partir aux frontières des parentèles, et même des villages entiers, fut le cadre de cette intégration civique $^{42}$. Léon Hennet a identifié, aux archives de Vincennes, vingt-huit de ces femmessoldats, voire femmes-officiers ${ }^{43}$ : il serait certainement possible d'y ajouter quelques unités, sans que le cours général de ces destins singuliers soit bouleversé.

31 Le contexte de l'entrée en guerre de la France, qui n'est pas encore constituée en République, et de la déclaration de la "patrie en danger ", qui change le cours de la Révolution, est celui d'une démocratisation incontestable de la force armée sous le signe de l'urgence. Le temps lent, progressif et linéaire, celui du débat et de la réforme, est suspendu, pour laisser place à une contraction du délai entre la décision et l'action ${ }^{44}$, et à une spirale qui ramène à un visage de la guerre antérieur à la professionnalisation opiniâtrement poursuivie par la monarchie administrative. Ce qui est alors fortement contesté par les partisans de la "guerre populaire» dans ce processus de révolution militaire, c'est la séparation du civil et du militaire ${ }^{45}$ dont la marque tangible est l'encasernement; c'est la manœuvre savante assimilée à un processus de déshumanisation et de mise en servitude ${ }^{46}$; c'est le monopole des armes par une caste bureaucratique dont la marque tangible est l'arsenal ; c'est l'éloignement prolongé de la terre des ancêtres qui dissout le socle de la citoyenneté "à l'antique », la terre et la famille.

À travers la rhétorique de la guerre en masse (notion passablement différente de la guerre de masse) c'est le fantasme de la horde gauloise, nourri aux références antiques de César et de Tacite, qui s'impose comme représentation de la guerre populaire : c'est le camp où bivouaquent le temps d'une campagne les volontaires issus de la France profonde, venus faire la guerre en famille ${ }^{47}$; c'est enfin et surtout le réinvestissement du débat récurrent sur l'alternative entre le choc et le feu, les tenants du premier terme préférant le combat à l'arme blanche, qui fait davantage ressortir la bravoure individuelle et l'initiative personnelle, tandis que l'arme à feu est l'arme des lâches et... des esclaves ${ }^{48}$ ! Singulier retournement auquel l'opinion publique a été acculturée tout au long du XVIII siècle par ce discours foncièrement critique du processus de révolution militaire, dont le fusil est justement l'emblème. Mesnil-Durand, en 1774, va reprendre et renouveler ces thématiques, en les reliant encore plus nettement au caractère national ; le corps-à-corps à la baïonnette est le type de combat qui sied le mieux à un soldat français parce qu'il exprime son esprit d'indépendance et sa bravoure ${ }^{49}$.

Mesnil-Durand est le contradicteur principal de Guibert ; mais c'est dans sa doctrine que vont puiser les révolutionnaires adeptes de la guerre populaire et de la déprofessionnalisation des armées. Il est quasiment oublié aujourd'hui, il n'est même plus mentionné dans les grandes anthologies de la pensée militaire, alors que Guibert est globalement considéré comme l'oracle des guerres de la Révolution et de l'Empire; l'historiographie a des parcours sinueux... La presse patriote répand cette valorisation de la pique comme arme par excellence des hommes libres. Le Père Duchesne théâtralise cette pantomime martiale :

[...] il faut que les braves sans-culottes qui sont maintenant les plus forts, se servent de leurs piques, qu'ils exterminent quiconque voudra sortir du cercle qui lui a été 
tracé par la loi. Qu'ils fassent une guerre ouverte à tous ceux qui ont vécu des abus de l'ancien régime [...]. Oui, mes amis, braves sans-culottes, suivez-moi, oui, foutre, armez-vous de vos piques, que la terre en soit hérissée. Je marche à votre tête, le Père Duchesne à votre tête, vous irez renverser les trônes de tous les tyrans, pas un autrichien, pas un aristocrate n'échappera à votre vengeance. Je vous réponds, foutre, à la fin de ma campagne, de rapporter au bout de ma pique, la tête de Français dernier, roi de Hongrie et de Bohême, et de la présenter à Madame Veto ${ }^{50}$ [...]. puis Bouchotte, vont faire abonner massivement les armées aux journaux sans-culottes, principalement celui d'Hébert ${ }^{51}$, mais il y en eut d'autres. Un conventionnel du Nord, imprimeur et journaliste par ailleurs, Armand Guffroy, préconise l'usage d'un autre type d'arme blanche, la francisque ${ }^{52}$. C'est une "petite hache» moins coûteuse et plus maniable qu'un sabre; c'est une "guillotine portative » dont même des femmes et des enfants peuvent faire usage. Il faut « se désaccoutumer du fusil », et cette arme convient bien à la guerre populaire imaginée par les radicaux. Les petits « combats de poste » ne conviennent pas à un républicain, un républicain doit « vaincre en masse ». La francisque est surtout l'arme de nos ancêtres les francs. Il faut absolument « faire la guerre comme la faisaient nos aïeux ", une guerre primitive, qui se détourne résolument de la guerre savante et professionnelle :

[...] il n'y a pas d'exemple à apprendre pour vaincre avec la francisque [...] celui qui a des bras devient tout de suite en l'état d'aller à l'ennemi...Que l'attaque commence par l'artillerie volante, par les bataillons disciplinés [...]; puis, après quelques heures de combat, que nos frères à piques, haches, francisques, bâtons, faux, fondent, comme un torrent, sur l'armée catholique cernée ; tandis que les bataillons disciplinés, cassant le biscuit et buvant du rogomme, se tiendront prêts à recommencer la carmagnole; quand nos frères en masse les auront mis en branle ; la nuit, repos ; et, à la pointe du jour, combat nouveau et toujours alternatif jusqu'à l'extermination complète ; c'est ainsi qu'on fait une battue de bêtes féroces ${ }^{53}$.

Cette scénarisation de la " guerre populaire ", qui n'est pas le fruit d'une radicalisation du processus révolutionnaire, mais la projection d'un imaginaire inversé de la «guerre en dentelles ", va se fracasser sur les réalités des premiers affrontements de terrain, et prendre l'aspect inquiétant des "paniques». Symptomatique de cette époque est la panique qui accompagne, le 29 avril 1792, la retraite des troupes de l'armée du Nord. Le meurtre, consécutif à celle-ci, du général Dillon est l'illustration de ce processus de justice expéditive inséparable du raccourcissement de l'intervalle temporel entre la décision et l'action, qui est la marque de la radicalité. L'entrée chaotique dans le conflit, contrairement aux reconstructions héroïques largement postérieures, allait initialement provoquer un véritable traumatisme, y compris chez les principaux dirigeants révolutionnaires, surtout lorsque ces derniers, à l'image de Saint-Just ou Carnot, sont au fait des réalités d'une campagne militaire.

Une des premières mesures à prendre pour rétablir une armée ordonnée (qui soit le reflet d'un corps civique recomposé) c'est de séparer la chose civile de la chose militaire. Cette séparation exige en préalable la sortie des femmes du camp militaire :

Un fléau terrible détruit nos armées; c'est le troupeau de femmes et de filles qui sont à leur suite; il faut compter qu'il y en a autant que de soldats; les casernes et les cantonnements en sont engorgés; la dissolution des mœurs y est à son comble ; elles énervent les troupes et détruisent par les maladies qu'elles y apportent, dix fois plus de monde que le fer des ennemis. Nous ne doutons pas que ce ne soit la principale cause de l'affaiblissement du courage. Il est instant que vous fassiez sur 
ce point une loi de la plus grande sévérité. L'abus n'est point facile à détruire ; nous, vos députés, ne le pourrions peut-être pas, sans l'autorité d'une loi très forte et très menaçante. Celle qui existe aujourd'hui est pour eux; elle prescrit de loger les femmes des soldats mariés. À Douai, où nous avons vu, dans un temps, la garnison réduite à 350 hommes, il y avait près de 3000 femmes dans les casernes, au point qu'il n'y avait pas une place vide pour les nouveaux corps qui revenaient de l'armée de Dumouriez. Nous insistons sur ce point, parce que l'armée est perdue si vous n'apportez le plus prompt remède à ce principe de dissolution ${ }^{54}$. conflit de longue durée, la réorganisation du système d'armes allait suivre la recomposition du corps civique.

\section{La République récupère le monopole sur la fabrication et la circulation des armes}

L'été 1792, celui de la proclamation de la Patrie en danger, fut bien l'été des piques. La pique porte tout à la fois l'argument utilitaire, et l'argument symbolique ; instrument peu coûteux à fabriquer, il est la marque de la vigilance révolutionnaire, et ces considérations l'emportent tout d'abord sur toute réflexion concernant son usage tactique. Lorsque des citoyens du faubourg Saint-Antoine viennent faire hommage à l'Assemblée législative des piques qu'ils ont fait construire pour combattre les ennemis de la Constitution, c'est bien le symbole révolutionnaire qui est brandi :

Nous sommes prêts à purger la terre des amis du Roi, et à le contraindre lui-même à ne plus nous tromper [...]. Rendez à cette cité nos braves Gardes-Françaises; recevez nos piques et notre dévouement pour faire respecter la volonté générale; c'est ce qui peut sauver l'Empire...55

Depuis l'été 1791 et la déclaration de Pillnitz, la question de l'armement des milices citoyennes est posée. Certes, on rappelle bien qu'il s'agit d'un « armement civique » pour la défense de l'État, et non du droit soumis à conditions (droit positif ou « droit modifié ») de porter des armes pour sa sécurité personnelle. L'organisation et l'équipement de la force publique est un problème constitutionnel, le permis de port d'armes est affaire de réglementation policière.

Toutefois, la circulation des armes brouille ce que la législation s'efforce de fixer. Le contrôle, donc les éventuelles restrictions apportées à cette circulation, contredit un autre principe fondamental de la réforme de l'État, celui de la liberté du commerce. Dans la séance de l'Assemblée Constituante du 23 septembre 1791, Goudart, rapporteur du Comité d'agriculture et de commerce, avait rappelé qu'aucun obstacle ne devait être apporté au cours ordinaire du commerce, à la notable exception des armes et munitions de guerre, des matières d'or et d'argent en lingots, et des espèces monnayées qui avaient cours dans le royaume.

Mais, dans le climat d'intense mobilisation patriotique consécutif à Varennes et à Pillnitz, nombre de municipalités ont entravé la liberté commerciale et, sous prétexte de l'interdiction d'exporter des armes et des munitions de guerre, elles se sont opposées à la sortie de différents objets inutiles à la défense des frontières.

Et Goudart énumère tous ces objets qui peuvent être considérés comme "armes » - ou plutôt qui peuvent être considérés comme "produits stratégiques", mais que l'on ne peut cependant soustraire au marché ${ }^{56}$. Ce sont les pierres à fusil, «que nous avons 
tellement en abondance que nous pourrions en fournir à pratiquement toutes les nations européennes "; les fusils de chasse, "qui ne peuvent servir ni aux gardes nationales, ni aux troupes de ligne » (ces fusils viennent de Liège ou d'Allemagne) ; les sabres, les épées et couteaux de chasse "dont les lames de fabrication étrangère ont été montées en France "; la poudre de chasse, "si facile à distinguer de la poudre à munition et de la poudre à canon ; le salpêtre « formé en abondance par notre sol et notre commerce dans l'Inde. Nous en avons tellement que nous avons été obligés de repousser le salpêtre étranger. »

Ainsi, le décret qui est adopté à la suite du rapport de Goudart réserve-t-il les contrôles et prohibitions de circulation aux seuls fusils de munition, voire aux seuls modèles réglementaires type 1777 portant le poinçon de l'État. Quant aux autres types d'armes en circulation, et pouvant éventuellement être considérées comme armes offensives, il n'est alors aucunement fait allusion aux piques.

Si la distinction reste de mise une année plus tard, le regard porté par les autorités sur la circulation des armes a totalement changé. Le 11 juin 1792, Lazare Carnot présente un projet de décret qui vise à l'armement de tous les citoyens inscrits sur les registres de la Garde nationale. Concrètement, ces derniers présenteraient aux « armuriers régnicoles et étrangers » des bons en échange desquels ils recevraient des fusils - sans plus de détails sur la qualification des fusils - payés 35 livres pièce aux dits armuriers. Le caractère relativement flou de la mesure est immédiatement corrigé par un second décret, présenté par Carnot-Feulint, qui passe alors pour le véritable expert en affaires militaires. Il demande que les armes distribuées soient de « bonnes armes », et pour cela il faut veiller à ce que tous les arsenaux, et pas simplement les commerces spécialisés, soient toujours bien approvisionnés. Quant à la liberté du commerce, elle ne doit plus être invoquée à l'encontre du contrôle de toute la palette des armes, qui peuvent désormais être considérées comme armes de guerre :

Article 1: la sortie à l'étranger de toutes armes et munitions de guerre est et demeure prohibée. Sont compris dans cette prohibition les fusils et la poudre de chasse, les pistolets de poche et d'arçon, les épées, sabres et couteaux de chasse... ${ }^{57}$

Mais le décret est également beaucoup plus explicite quant à la fabrication et à l'usage des fusils :

Article 3 : le pouvoir exécutif doit ordonner l'inventaire de tous les fusils qui se trouvent dans les arsenaux et magasins nationaux, dont le calibre, la longueur, la forme, le défaut de bayonnette pourraient les rendre impropres à leur usage dans l'armée, mais qui pourraient être d'une grande utilité entre les mains des citoyens habitant les campagnes des départements-frontières. Ces fusils seront réparés, on fera des moules à balles pour les mettre au calibre. Ces fusils ne seront distribués qu'après un décret du Corps Législatif, et marqués des lettres A.N. (armes nationales).

On voit poindre également le désarmement des suspects, en l'occurrence ici les émigrés, susceptibles de détenir des armes de par les grades militaires qu'ils occupaient auparavant :

Article $4:$ il sera fait un inventaire sous huitaine des fusils de toute espèce qui peuvent se trouver dans les maisons des émigrés. Il sera envoyé au directoire du département qui l'enverra au Pouvoir Exécutif, qui en donnera connaissance au Corps Législatif.

Enfin, une hiérarchisation de l'équipement est préconisée, en fonction d'une réorganisation totale de l'instrument militaire, qui trouvera ultérieurement son orientation par l'amalgame :

Article 5 : Les fusils modèle 1777 existants dans les magasins nationaux ne pourront être distribués aux troupes de nouvelle levée sous aucun prétexte, tant qu'on 
pourra leur en fournir d'autres, neufs ou réparés. La seule exception est que ces troupes soient employées contre les ennemis extérieurs. armes, dans le cadre ici de la monarchie constitutionnelle, et de façon bien plus étendue par la suite, dans le cadre du gouvernement révolutionnaire. La question des piques s'insère dans ce débat général sur la réinstauration du monopole. Le grand discours de Lazare Carnot sur la fabrication des piques, du $1^{\mathrm{er}}$ août 1792, dans lequel on a voulu voir la consécration de l'usage de l'arme par excellence des sans-culottes, est en fait une dissociation du principe et de l'usage ${ }^{58}$. Pour le principe, « la pique est en quelque sorte l'arme de la liberté, parce que c'est la meilleure de toutes entre les mains des Français, parce qu'enfin elle est peu dispendieuse et promptement exécutée. » On a pu se prévaloir de l'image pour en proposer une généralisation qui répondait à une nécessité ; «la pénurie des armes à feu, qui a excité tant de plaintes et fait naître de si justes inquiétudes, avait déterminé plusieurs personnes à vous proposer la création de quelques corps de piquiers et lanciers. " Mais Carnot balaye cet argument, en en faisant une rumeur entretenue par le parti de la Cour ; « cette pénurie avait été jusqu'ici fort exagérée par les ministres, et [...] le nombre de fusils disponibles était plus que suffisant pour armer toutes les troupes employées à la défense des frontières. » Aussi, "sans rejeter le projet de création d'un corps de piquiers, votre commission a pensé qu'on pouvait s'en passer en ce moment. » Et le reste du discours développe le principe du nouveau système militaire qui est celui de la Nation en armes, celui que saluera ultérieurement Jean Jaurès dans l'armée nouvelle:

Partout, en effet, où une section particulière du peuple demeure constamment armée, tandis que l'autre ne l'est pas, celle-ci devient nécessairement esclave de la première, ou plutôt l'une et l'autre sont réduites en servitude par ceux qui savent s'emparer du commandement; il faut donc absolument, dans un pays libre, que tout citoyen soit soldat, ou que personne ne le soit. Mais la France, entourée de nations ambitieuses et guerrières, ne peut évidemment se passer de la force armée : il faut donc, suivant l'expression de J.-J. Rousseau, que tout citoyen soit soldat par devoir, et aucun par métier. Il faut donc qu'à la paix, au plus tard, tous les bataillons de la troupe de ligne deviennent bataillons de la Garde nationale ; que les uns et les autres n'aient plus qu'un même régime, une même solde, un même habit: alors, vous épargnerez 40 millions par an; alors disparaitra ce germe de division qu'on cherche à semer sans cesse entre les soldats citoyens et les citoyens soldats; alors chaque corps nommera ses officiers, et l'on ne verra plus ceux-ci vendus au pouvoir exécutif passer à l'ennemi et trahir la patrie qui les a comblés de ses bienfaits. Ce vœu, j'ose le dire, est celui de la Nation entière; il n'est personne qui ne sente que la liberté française ne peut s'établir de fait que par la chute de cette dernière colonne du despotisme.

Ainsi, le discours qui devait marquer le triomphe de la pique révolutionnaire est en réalité son enterrement, non seulement pour son peu d'efficacité tactique, mais aussi au nom des principes de l'armée nouvelle. Le fusil est bien l'arme par excellence du citoyen. Restait à répondre à une demande croissante, du fait de l'effort de guerre, et à en réguler la circulation pour conserver et renforcer le monopole. Les mesures qui vont dans ce sens vont être adoptées très rapidement, dès le 13 octobre 1792. Laurent Lecointre, au nom de la section de l'armement du Comité de la Guerre de la Convention, qui a pris la suite de la Commission des armes, instituée à la suite du décret sur la Patrie en danger (11 juillet 1792) va s'y employer. Dans les manufactures d'armes qui appartiennent à la République (surtout Saint-Étienne, Charleville, Maubeuge, Tulle, et Moulins), il ne doit se 
fabriquer d'armes que pour le compte de la République. C'est la République qui passe en outre les marchés avec les entrepreneurs particuliers qui fabriquent les armes à feu :

À partir de ce jour, dans toutes les manufactures nationales d'armes de la République, il ne sera fabriqué d'armes que pour le compte de l'État, en vertu des commandes ordonnées par le Ministre de la Guerre, ou de marchés passés entre les entrepreneurs et lui ${ }^{59}$.

C'est l'État qui répartit les travaux, et qui coordonne les travaux des ouvriers (qui reçoivent un statut particulier) selon la nature des armes demandées. Celles-ci sont réparties selon des modèles standardisés : le modèle $n^{\circ} 1$, ce sont les fusils type 1777 , ou 1763 (fusils de munitions réglementaires). Chaque fusil est facturé 42 livres pour le type 1777, et 35 livres pour le type 1763. Tous les autres fusils et pistolets, «montés ou non montés ", ainsi que toutes les pièces d'armement qui se trouvent en dépôt dans les places de guerre, seront transférés aux manufactures nationales, pour y être réparés et homologués.

La manufacture d'armes devient la plus grande entreprise proto-industrielle de l'époque, et c'est sur ce modèle que l'on instaure ultérieurement la manufacture d'armes de Paris. Cet établissement qui coiffe plusieurs structures éparses dans la capitale (Arsenal, forges du Luxembourg, des Tuileries, commissariat de Meudon, péniches amarrées à Javel, poudrière de Grenelle, etc) trouve son origine dans l'initiative prise par Guyton-Morveau le 14 juin 1793. Guyton est le premier président du Comité de salut public en avril 1793, et il dispose de tout un réseau de scientifiques et d'industriels qui vont promouvoir la centralisation de l'effort de guerre ${ }^{60}$. Politiquement, il est proche de Carnot et de Barère ${ }^{61}$, le même Barère qui, dans le cadre de la levée en masse d'août $1793^{62}$, fixera comme objectif à la manufacture d'armes «mille fusils par jour ${ }^{63}$. " La production d'armes a fait entrer l'économie française dans l'ère de la production de masse. Les ateliers de maîtres et ouvriers-armuriers sont regroupés et uniformisés sous un régime de travail de 14 heures par jour, avec un jour de repos par décade.

« Tous les armuriers, arquebusiers, serruriers, taillandiers, charrons, [...] sont mis en état de réquisition permanente, pour la confection et le prompt achèvement de tous les affûts, caissons, trains et chariots d'artillerie ${ }^{64}$. » C'est par l'intermédiaire de la Commune et des sections parisiennes que le débat sur l'extension du champ de la réquisition des armes, et de la diversification de leur usage tactique est relancé. Cette demande trouve des échos favorables au sein du Ministère de la Guerre, qui cherche alors à relancer un type de " guerre populaire » différent de l'« armée nouvelle » préconisée par les responsables du Comité de salut public. De nouveau, l'argument de la pénurie d'armes à feu est brandi pour justifier ces spéculations tactiques. C'est Drouet qui s'interroge sur l'utilisation des arquebuses, ces armes à feu archaïques que l'on n'utilisait plus guère que comme armes d'apparat, le 8 juillet 1793 :

De toutes parts, on se plaint du défaut d'armes. Je connais un moyen d'en trouver. On laisse enfouie dans les magasins une grande quantité d'arquebuses. Ces armes, mises dans les mains de chasseurs habiles, deviendraient bien meurtrières et bien dangereuses contre les ennemis ${ }^{65}$.

Les partisans de la pique reviennent à l'offensive. Le 25 août 1793, le Conseil Général de la Commune présente au ministre de la Guerre diverses observations relatives aux piques, en lui soumettant un modèle rénové de cette arme, ainsi qu'un javelot à employer contre la cavalerie ennemie ${ }^{66}$. L'administration de la manufacture d'armes est théoriquement coordonnée entre le Conseil Général de la Commune et la Commission des Armes du Comité de salut public. Le Conseil général désigne six commissaires qui se joignent aux 
24 commissaires désignés par les sections de Paris, pour discuter du prix des matières premières nécessaires à la fabrication des armes, sous la supervision des quatre délégués désignés par le Comité de Salut public (Périer, Berthollet, Fourcroy et Laffitte). Les tensions sont manifestes, certes autour de la fixation du maximum des salaires et des conditions de réquisition de la main d'œuvre qualifiée, comme il est généralement avancé ${ }^{67}$, mais aussi, et cela est beaucoup moins mis en valeur, autour de la nature des matières premières et des produits finis. Billaud-Varennes, membre du Comité de salut public, tonne à la tribune de la Convention le 20 septembre 1793, après avoir entonné le lamento habituel sur la pénurie d'armes :

Que font donc les ouvriers en fer? Est-ce qu'ils fabriquent des canons de fusil?

NON.

Il faut que les ouvriers serruriers ne soient plus occupés qu'à fabriquer des armes.

Les serrures de la Liberté sont les baïonnettes et les fusils ${ }^{68}$.

51 Danton avait demandé qu'une somme de cent millions de livres soit mise à la disposition du ministre de la Guerre pour cette fabrication, rappelle Billaud-Varennes, mais on ne voit toujours pas les investissements. Le conflit de compétences se résout par la suppression ultérieure du Ministère de la guerre en avril 1794, et son remplacement par une Commission des Armes et des poudres qui marque la prépondérance du Comité de Salut public. Avec elle, s'impose la nécessaire centralisation de l'effort de guerre et la rationalisation de la production des armes.

\section{Conclusion : la Patrie en danger, formation d'un mythe civique}

52 Au cours de l'été 1799, la question de la Patrie en danger redevient une question d'actualité, avec les menaces d'invasion du territoire par les troupes de la Seconde Coalition $^{69}$. Le peintre Guillon-Léthière, métis d'origine guadeloupéenne, de sensibilité néo-jacobine, compose une grande toile pour le salon de 1800, L'enrôlement des volontaires ou la Patrie en danger ${ }^{70}$. La scène exprime l'imaginaire républicain imprégné de l'élan guerrier qui le fonde et le justifie. Elle offre une allégorie de la République comme un gigantesque camp militaire ordonné, ainsi que Joseph Servan l'avait anticipé dès 1780 dans Le soldat-citoyen ${ }^{71}$. Le décor est un environnement néo-classique entremêlé d'éléments qui renvoient à une symbolique empruntée à l'antique, mais modernisée ; la scène centrale se déroule bien sur un forum dominé par une acropole où les temples se découpent dans la lumière, mais c'est aussi une cité fortifiée avec des remparts, une citadelle, et des bâtiments qui évoquent les villes italiennes (des églises, et le bâtiment qui ferme un des côtés du forum, qui peut tout aussi bien être la Curie romaine que le palazzo civique des républiques médiévales). On remarque également que l'un des côtés du forum s'ouvre largement sur un espace maritime sillonné de vaisseaux, et dominé par une très haute tour fortifiée, tout à la fois phare et beffroi. C'est l'esprit du « républicanisme moderne ", un idéal qui ne renie pas le républicanisme antique, mais qui ouvre la Cité sur l'Histoire et sur le grand large.

La mobilisation civique et les volontaires ainsi exaltés dans la composition répondent à cet aggiornamento du patriotisme classique. Le volontaire, puis le conscrit, se substituent à l'image du libre milicien des montagnes d'Helvétie, des forêts de Germanie, ou des étendues sauvages du Nouveau Monde. Le décor urbain, qui borne la scène principale sur deux côtés, ouvert largement sur les espaces océaniques (sillonnés de part en part par des 
navires de natures diverses) pour le troisième, est en rupture avec l'environnement naturel, qui signalait une époque désormais dépassée de l'affirmation du droit. La Cité est ordonnée par l'énoncé de la loi. La scène centrale est ordonnée autour de trois groupes ; les guerriers effectuent un mouvement d'ensemble qui évoque le serment et les leçons de David $^{72}$, les civils au premier plan, et le magistrat collectif, les représentants du peuple, qui fait le trait d'union entre les deux ensembles. La sphère civile est individualisée par trois personnages représentatifs des seules conditions sociales reconnues par la République moderne; un vieillard ceint d'une couronne de lauriers, un enfant qui transporte des sabres et une pique, une jeune fille qui transporte une grande quantité de fusils. La communauté civique est une communauté idéalement recomposée et ordonnée. La sphère civile est bien distincte de la sphère militaire, mais sans que cette distinction implique une quelconque domination de la seconde sur la première. Le processus de séparation des deux mondes, qui était inscrit au cœur de la modernisation de l'État ${ }^{73}$, et du processus parallèle de professionnalisation des forces armées, est bien ici repris par le projet républicain, avec les soldats citoyens et la mobilisation générale des civils, mais sans que celui-ci implique une inégalité de statuts, ou une différenciation des espaces. Deux personnages, placés en pleine lumière, assurent le lien entre les deux mondes. Récepteur des dons patriotiques et ordonnateur de la cérémonie, le représentant en mission, entouré des magistrats élus et ceints de tricolore pose sa main sur le bras d'un simple citoyen, geste rappelé par le personnage central du second groupe, l'officier qui demande à son camarade qui le presse de s'embarquer un répit supplémentaire pour embrasser sa compagne. En contrepoint de ce rôle démobilisateur de l'épouse, la jeune fille du tout premier plan qui transporte les fusils tempère une lecture trop univoque de la répartition sexuée des rôles dans la Cité républicaine. Cette figure, que l'on peut considérer comme transgressive, est la seule mention, bien en évidence, du fusil, alors que la composition est saturée d'armes blanches, symboles phalliques certes, mais encore ornements désormais indissociables, mais distanciés, de la rhétorique révolutionnaire.

Évocation rétrospective - et donc forcément tronquée - de l'enthousiasme qui accompagna l'épiphanie républicaine, ce regard nostalgique porté sur une communauté exempte de contradictions, est aussi une apologie du processus par lequel les nouvelles institutions politiques ont récupéré le monopole sur les armes. Nous sommes sortis du cadre du droit naturel pour entrer dans celui du corps civique recomposé. La circulation des armes s'ordonne ldu sol vers le lieu d'exercice de la démocratie représentative, la tribune où le représentant du peuple procède à la distribution, pour culminer dans la double gestuelle inversée (à la fois verticale et horizontale) de l'érection du sabre et du doigt brandi vers le grand large, qui rappelle que cette République moderne est aussi une République impériale.

\section{NOTES}

1. New York Journal, Supplement, 13 avril 1796, p. 1, Col.3, cité dans Stephen HALBRooK, A Right to Bear Arms: State and Federal Bills of Rights and Constitutional Guarantees, Westport, Connecticut, Praeger, 1989. 
2. Victor Davis HANSON, Carnage et culture, Paris, Flammarion, 2010 (édition originale, Carnage and culture : landmark battles in the rise of western power, 2001), p. 38.

3. Denis DIDEROT, Principes de politique des souverains, Paris, Garnier, 1875, tome II, article LXVII : "Sous quelque gouvernement que ce fût, le seul moyen d'être libre ce serait d'être tous soldats; il faudrait que dans chaque condition le citoyen eût deux habits, l'habit de son état et l'habit militaire. Aucun souverain n'établira cette éducation. », texte établi par Jules Assézat et Maurice Tourneux, p. 473.

4. Brian M. Downing, The Military Revolution and Political Change: Origins of Democracy and Autocracy in Early Modern Europe, Princeton University Press, 1992.

5. Joseph-Nicolas GUYOT, Répertoire universel et raisonné de jurisprudence civile, criminelle, canonique et bénéficiale, J. Dorez, Paris, 1775-1783.

6. $\mathrm{BNF}$, département des manuscrits, Édit du Roy qui confirme le réglement touchant le nettoyement des boues, et pourvoit à la seureté de la Ville de Paris et autres Villes, Paris, ms français 21711 , microfilm 9636. Le texte est transcrit dans le mémoire de maîtrise de Marie SAUMET, Le feu et le fer à Paris, de 1666 à la fin de l'Ancien Régime, Université Paris 1 Panthéon-Sorbonne, sous la direction d'Alain Cabantous, juin 2000, p. 112-114.

7. Joseph DE FLORENTIS, Histoire du fusil, Paris, Éditions De Vecchi, 1975.

8. Pascal BRIOIST, Hervé DREVILLON, Pierre SERNA, Croiser le fer. Violence et culture de l'épée dans la France moderne (XVI ${ }^{e}$-XVIII ${ }^{e}$ siècles), Seyssel, Champ Vallon, 2002.

9. Marie saumet, Le feu et le fer à Paris, de 1666 à la fin de l'Ancien Régime, Université Paris1 Panthéon-Sorbonne, mémoire de maîtrise d'histoire sous la direction d'Alain Cabantous, 2000, p. 8 et suivantes.

10. Ibid., p. 14-17.

11. Patrice BRET, « La fonderie de canons d'Indret. De quelques modes de circulation technique à la fin du XVIII" siècle », Quaderno d'Historia de l'Engenyeria, 10/2009, p. 53-66.

12. Joseph MARGERAND, Armement et équipements de l'infanterie française du XVI ${ }^{e}$ au XX $X^{e}$ siècles, Paris, Les Éditions militaires illustrées, 1945.

13. Jean CHAGNIOT, Paris et l'armée au XVIII e siècle. Étude politique et sociale, Paris, Economica, 1985.

14. Comme en témoigne la mode des parades et défilés militaires dans la plupart des villes françaises dans les années 1780. Un indice significatif est aussi la substitution progressive, dans les catalogues des maîtres-imprimeurs, des images pieuses par des représentations de soldats en uniforme, destinées à la décoration des logis populaires, à partir du milieu du siècle (voir le catalogue des imprimeurs de la ville de Chalon-sur-Saône au Musée Vivant Denon). Il faudrait également analyser les répertoires des théâtres, où la figure du militaire, qui ne joue pas seulement un rôle négatif, se généralise. Bien entendu, ces indices appellent une enquête plus systématique ; mais ils suffisent à mettre en doute la « militarisation » uniquement ramenée aux années révolutionnaires.

15. Gravure anonyme, «Formation de la garde, le 13 juillet 1789 », BNF, Paris, dans Michel VOVELLE, La Révolution française. Images et récit, Paris, Éditions messidor, 1986, tome 1, p. 139.

16. Ibid., p. 180 : Jean DuPLESSI-BERTAux, Pierre-Gabriel BERTHAult (d'après Jean-Louis Prieur), «Canons de Paris portés à Montmartre : le 15 juillet 1789 », 1802 ; aussi disponible sur Gallica : http://gallica.bnf.fr/ark:/12148/btv1b6942957g.

17. Roger DupuY, La Garde nationale et les débuts de la Révolution en Ille-et-Vilaine, Paris, Klincksieck, 1972, p. 68-81.

18. Guillaume LASCONJARIAS, Un air de majesté. Gouverneurs et commandants dans l'Est de la France au XVIII siècle, Paris, Éditions du CTHS, 2010, p. 303-310.

19. Jean-Baptiste DOnAtien DE VIMeUR, comte de Rochambeau, Mémoires militaires, historiques et politiques, Paris, Fain, 1809, p. 364. 
20. Bruno BENOIT, Roland SAUSSAC, Guide historique de la Révolution à Lyon (1789-1799), Lyon, Éditions de Trévoux, 1988.

21. Gravure Pierre-Gabriel BERTHAULT (d'après Jean-Louis Prieur), « Pillage de l'arsenal de Lyon, le 7 février 1790 », 1802, dans Michel Vovelle, Images et récit..., op. cit., tome 2, p. 82 ; aussi disponible sur Gallica : http://gallica.bnf.fr/ark:/12148/btv1b8411032m.r=.

22. Archives parlementaires (maintenant AP), tome 1, 7 août 1789, p. 301, intervention de d'Ambly.

23. Ibidem.

24. Ibid., p. 302.

25. Ibid., p. 301.

26. Médéric-Louis-Elie MOREAU DE SAINT-MÉRY, Description topographique, physique, civile, politique et historique de la partie française de l'isle Saint-Domingue, Saint-Denis, Publications de la Société française d'histoire d'outre-mer, Paris, 2004 (3édition), tome 1, p. 303.

27. Pamphile DE LACROIX, La Révolution de Haïti, Paris, Karthala, 1995 (Édition reprise de l'original, Mémoires pour servir à l'histoire de la Révolution de Saint-Domingue, Paris, 1819), p. 78.

28. Bernard GAINOT, Les officiers de couleur dans les armées de la République et de l'Empire (1792-1815), Paris, Karthala, 2007.

29. Russell воuchaRD, Les armes de traite, Sillery, Éditions du Boréal Express, 1976, collection « Histoire populaire du Québec ».

30. Manuel covo, Commerce et révolutions dans l'espace atlantique. États-Unis-Saint-Domingue. 1784-1806, Thèse d'histoire, EHESS, sous la direction de François WEIL, novembre 2013.

31. Marcel CHATILLON, dans Hélène Lafont-Couturier (dir.), Regards sur les Antilles, collection Marcel Chatillon, Bordeaux, Éditions RMN, 1999, p. 225.

32. Thomas MAdiou, Histoire d'Haïti, Éditions Henri Deschamps, Port-au-prince, 1989, t. 1, p. 317.

33. Ibidem.

34. Michel DescourTiLz, Voyage d'un naturaliste en Haïti 1799-1803, présenté par Jacques Boulenger, Paris, Plon, collection, « Nouvelle bibliothèque des voyages », 1935.

35. Michel vovelle, Images et récit..., op. cit., tome 1, p. 242 : «Avant-garde des femmes allant à Versailles, 5 octobre 1789 », gravure de la BNF ; aussi disponible sur Gallica : http://gallica.bnf.fr/ ark:/12148/btv1b8410838j.

36. Ibid., p. 243, « Départ des héroïnes de Paris pour Versailles, le 5 octobre 1789 », gravure de la BNF.

37. Michel DELON, «Jeanne Laisné, héroïne sadienne », dans « Figures de l'histoire de France dans le théâtre au tournant des Lumières 1760-1830», études présentées par Paul Mironneau et Gérard Lahouati, Studies on Voltaire and the Eighteenth century, 7/2007, p. 81-87.

38. Donatien-Alphonse-François DE SADE, Jeanne Laisné ou le siège de Beauvais, tragédie en 5 actes, dans Oeuvres complètes, tome 13 («théâtre $1 »)$, Paris, Jean-Jacques Pauvert, 1991. Les citations de la pièce qui suivent renvoient à cette édition.

39. Colette BEAUnE, Jeanne d'Arc, Paris, Perrin, 2004.

40. Paule-Marie DUHET, Les femmes et la Révolution (1789-1794), Paris, Gallimard, 1971, collection "Archives », p. 116. L'auteur attribue cette pétition à Pauline Léon, sans références explicites.

41. Henriette PERRIN, "Le club de femmes de Besançon », Annales révolutionnaires, 1917, t. IX, p. 629-653, et 1918 ; t. X, p. 37-63, 505-532, et 645-672.

42. Jean-Paul BERTAUD, La révolution armée. Les soldats-citoyens et la Révolution française, Paris, Robert Laffont, 1979, p. 79 et suivantes.

43. Charles-Louis. CHASSIN et Louis HENNET, Les volontaires nationaux pendant la Révolution, Paris, Le Cerf, 1903 ; Voir également Raoul BRICE, La femme et les armées de la Révolution et de l'Empire (1792 1815), Paris, Ambert, s. d. (listes p. 313-316).

44. Jacques Guilhaumou a particulièrement bien approfondi cette question à travers la figure du législateur-philosophe, voir notamment: Jacques GuILHAUmou, L'avènement des porte-parole de la 
République (1789-1792). Essai de synthèse sur les langages de la Révolution française, Villeneuve-d'Ascq, Presses universitaires du Septentrion, 1998.

45. Voir le volume Benjamin DERUELlE, Bernard GAINOT (dir.), La construction du militaire, Savoirs et savoir-faire militaires à l'époque moderne, Paris, Publications de la Sorbonne, 2013.

46. Arnaud GUIGNIER, L'honneur du soldat: éthique martiale et discipline guerrière dans la France des Lumières (1748-1789), Seyssel, Champ Vallon, 2014.

47. Michel vovelLE, Images et récit..., op. cit., tome 3, p. 241 : « camp républicain ».

48. Hervé DRÉVILLON, L'individu et la guerre. Du chevalier Bayard au soldat inconnu, Paris, Belin, 2013, p. 145-209.

49. François-Jean de MESNIL-DURAND, Fragments de tactique, ou six mémoires...sur les chasseurs et sur la charge, précédé d'un Discours Préliminaire sur la Tactique et sur les Systèmes, Paris, Librairie Ambert, 1774, «Discours préliminaire» p. XL et XLI : «En vain la tactique Française - souligné dans le texte - sera connue, et tant bien que mal imitée; ce n'est qu'à la France qu'elle donnera des victoires; cela est d'autant plus infaillible, que ce style de dispositions et manœuvres trop chargeantes, n'est point fait pour nos ennemis. De même que nous ne pouvons acquérir le phlegme, l'ordre, la fermeté des Allemands et des Russes, ils ne parviendront point à faire des charges Françaises. En suivant le système du feu, et des manœuvres difficiles et compliquées, nous devons être toujours battus, à moins qu'un heureux concours de circonstances favorables ne fasse dans quelques occasions particulières exception à la règle. En suivant le système de la charge et des manœuvres simples et faciles, nous devons être toujours vainqueurs, comme l'ont été aussi ceux de nos Généraux qui ont pu ne point trop s'écarter de ces principes. »

50. "L'arrêt de mort de tous les tyrans, ou déclaration de guerre du Père Duchesne ", Père Duchesne, $n^{\circ} 126$, Archives de la Révolution française..., op.cit., voir également sur cette question Renaud FAGET, Commander en 1792-1793, le cas Houchard, thèse de l'Université Paris1, sous la direction de Bernard Gainot, décembre 2011.

51. Jean-Paul BERTAUD, la Révolution armée: les soldats-citoyens et la Révolution française, Paris, Robert Laffont, 1979, p. 94.

52. Armand GUFFROY, Le Rougyff ou le franc en vedette $n^{\circ} 52$, p. 2, cité par Céline NUSSE, Rougyff ou le France en vedette d'Arnaud Guffroy. Un journal subventionné à vocation populaire en l'an II, Université Paris 1 Panthéon-Sorbonne, mémoire de maîtrise sous la direction de Jean-Paul Bertaud, 1995, p. 98.

53. Ibidem.

54. Rapport de Carnot et Duquesnoy sur les femmes suivant l'armée, 16 avril 1793, dans Jean-Paul CHARNAY (présentation), Lazare Carnot, Révolution et mathématique, Paris, Cahiers de l'Herne, 1985, p. 126-127.

55. Moniteur Universel, réimpression, tome 11, p. 367, séance du 11 février 1792.

56. Ibidem, t. 9, p. 752.

57. AP, tome 45, décret du 11 juin 1792, sur rapport de Carnot le jeune, 11 juin 1792, p. 99, citation et suivantes.

58. Lazare CARNOT, Rapport sur une fabrication de piques, $1^{\mathrm{er}}$ août 1792, dans Lazare Carnot, Révolution et mathématique, op. cit., t. 2, p. 108-111, citation et suivantes.

59. Moniteur Universel, réimpression, t. 14, p. 198, séance du 12 octobre 1792.

60. Patrice BRET, L'État, l'armée, la science. L'invention de la recherche publique en France (1763-1830), Rennes, PUR, collection "Carnot», 2002. Patrice Bret coordonne un numéro spécial des Annales historiques de la Révolution française, qui sera consacré à Guyton-Morveau (publication prévue au début de l'année 2016).

61. Sur les positions de Barère dans cette séquence chronologique, je me permets de renvoyer à ma contribution aux Rendez-vous de l'Histoire à Blois du 11 octobre 2013, « Révolutionner la gloire. Acculturation nationale et valeurs militaires en l'an II ", dans Benjamin Deruelle, Arnaud 
Guignier (dir.), Cultures et identités combattantes en Europe, de la Guerre de Cent ans à la Seconde Guerre mondiale, Paris, Publications de la Sorbonne, à paraître.

62. Le texte du décret sur la levée en masse se trouve dans AP, « Projet de décret portant appel au Peuple français ", t. 72, p. 688-690.

63. Selon le rapport de Guyton-Morveau du 14 pluviôse an III (3 février 1795), la manufacture d'armes a produit en réalité 154630 fusils et pistolets en treize mois. Voir Jeff HORN, « Mille fusils par jour. L'économie politique de la production militaire à Paris durant l'ère de la Terreur », dans Michel Biard (dir.), Les politiques de la Terreur. 1793-1794, Rennes, PUR et Société des études robespierristes, 2008, p. 281-290.

64. , "Arrêté de la Commune de Paris, 16 juin 1793 », Le Moniteur Universel, n 170, mercredi 19 juin 1793 (réimpression t. 16, p. 667).

65. Moniteur Universel, réimpression, t. 17, p. 75. Séance du lundi 8 juillet 1793.

66. Ibid., p. 497, Commune de Paris, séance du 25 août 1793.

67. Jeff HORN, « Mille fusils par jour... », art. cit.

68. Moniteur Universel, op. cit., p. 708 et suivantes, débat à la Convention du 20 septembre 1793.

69. Bernard GAINOT, 1799, un nouveau jacobinisme? La démocratie représentative, une alternative à brumaire, Paris, Éditions du CTHS, 1998.

70. Le tableau se trouve au Musée de la Révolution française à Vizille : Guillaume GUILLON-LETHIÈRE , l'Enrôlement des volontaires ou la Patrie en danger, 1799, Huile sur toile, Inv. MRF 1985-14. Michel Vovelle en offre une reproduction dans Michel vovelLE, la Révolution française. Images et récit, op. cit., t. 4 p. 110-111, mais il l'attribue faussement à Gérard, et il l'intitule la levée en masse. Consultable sur le site : http://www.histoire-image.org/pleincadre/index.php?i=251.

71. Joseph SERVAN DE GERBEY, Le soldat-citoyen ou Vues patriotiques sur la manière la plus avantageuse de pouvoir à la défense du Royaume, dans le pays de la liberté, Neuchâtel, 1780.

72. Je pense tout particulièrement à La cérémonie des aigles, tableau de 1810 qui se trouve au Musée de l'Histoire de France (Versailles), mais le mouvement est plus dynamique chez GuillonLéthière.

73. Voir le volume Benjamin DERUELLE, Bernard GAINOT (dir.), La construction du militaire, op. cit.

\section{RÉSUMÉS}

La prolifération des armes au cours de la Révolution est fondamentale, mais elle se présente sous plusieurs aspects. Elle relève d'abord du principe de l'auto-défense, et, à ce titre, elle invoque le droit naturel. La possession d'une arme devient la prérogative du citoyen, elle accompagne donc les formulations du droit positif.

La dimension symbolique transcende toutefois la réglementation positive. La nature des armes en circulation renvoie non seulement à leurs usages, mais aussi aux représentations individuelles et communautaires auxquelles elles sont associées.

Enfin, le contrôle croissant de l'Etat sur la circulation des armes sous la monarchie administrative illustre la recherche du monopole de la violence légitime. Elle se décline de différentes façons : la réglementation des métiers, l'édification des arsenaux, le contrôle de la production. Cette tentative, parallèle à la révolution militaire, vole en éclats dans les premières années de la Révolution. La récupération du monopole sur la production et la circulation des 
armes, sur l'ensemble du territoire de la République, devient un enjeu majeur de la construction de l'Etat-nation.

The anarchical proliferation of arms among the population during a revolutionnary process is a basic question, but we have to consider it from many angles; self-defense (a principle of natural right), then a prerogative of citizenship (according to the evolutions of the positive right).

Nevertheless, the symbolic system is something else than the regulation system. The sort of arms wich are on the market are material ones, of well-defined usage, but also social and cultural objects, with individual and collective representations.

Finally, the increasing control of the monarchical State upon the market of arms express the monarchical search of state monopoly upon the legitimate violence. There are different faces of things: crafts regulation, arms factory building, arms production control. This attempt, at the same time as the military revolution, blow up during the early years of Revolution. The recovery of state monopoly upon the arms market all over the republican territory, are becoming major stakes for the Nation-building process.

\section{INDEX}

Mots-clés : auto-défense, arsenaux, manufactures d'armes, libre circulation des armes, réglementation du commerce des armes, armes blanches, armes à feu, Patrie en danger

Keywords : self-defense, arms factory, arsenals, free market of arms, trade in arms regulation, knifes, firearms, emergency state 